\title{
SPEECH BEHAVIOUR OF INTROVERT AND EXTROVERT PERSONALITY TYPES IN THE PARLIAMENTARY DISCOURSE
}

\author{
Olga V. Popova \\ Moscow State Linguistic University, Moscow, Russia
}

\begin{abstract}
The paper deals with the peculiarities of British politicians' speech behaviour in the frames of the parliamentary discourse. The research is based on the scripted monologic speeches and spontaneous dialogic speeches given by Prime Minister Teresa May and Labour Leader Jeremy Corbyn, during the PMQs session in the British Parliament on September 14, 2016. The first stage of the research is aimed at determining the levels of extraversion or introversion and emotionality of the speakers through the analysis of the non-verbal component of their speech behaviour such as eye contact with the audience, gestures and facial expressions when delivering scripted speeches in different situations - direct (in front of the audience) and mediated (on air) socially oriented communication. The methods of observation and comparison let refer the communicants to different psychological types: J. Corbyn's behaviour betrays the extrovert type of personality, while that of T. May demonstrates the characteristics of the introvert type. The second stage focuses on the speakers' verbal communication patterns when delivering spontaneous speech with the purpose of finding correlations between the psychological type of the speaker (extrovert or introvert, stable or emotional) and the preferred type of argumentation and strategies in debate. The analyzed material indicates the tendency of an extraverted type to rely on quotations and statistical data as a means of rational argumentation, while an introverted type tends to rely on subjective arguments gained through personal experience. The strategies of an extravert tend to be flexible, while the strategies of an introvert are characterized as rigid.

Key words: parliamentary discourse, argumentation, extraversion, introversion, temperament, speech activity, speech behaviour, speech strategy.
\end{abstract}

Citation. Popova O.V. Speech Behaviour of Introvert and Extrovert Personality Types in the Parliamentary Discourse. Vestnik Volgogradskogo gosudarstvennogo universiteta. Seriya 2, Yazykoznanie [Science Journal of Volgograd State University. Linguistics], 2018, vol. 17, no. 2, pp. 134-142. (in Russian). DOI: https://doi.org/ 10.15688/jvolsu2.2018.2.15

УДК 81 '42:82-54

ББК 81.006

Дата поступления статьи: 05.03.2018 Дата принятия статьи: 20.04.2018

\section{ОСОБЕННОСТИ РЕЧЕВОГО ПОВЕДЕНИЯ ЛИЧНОСТИ ИНТРОВЕРТНОГО И ЭКСТРАВЕРТНОГО ТИПОВ В ПАРЛАМЕНТСКОМ ДИСКУРСЕ}

\author{
Ольга Валентиновна Попова \\ Московский государственный лингвистический университет, г. Москва, Россия
}


ориентированного общения. С помощью методов наблюдения и сопоставления было выявлено, что коммуниканты относятся к разным психологическим типам: поведение Дж. Корбина указывает на его принадлежность к экстравертному типу личности, в то время как Т. Мэй демонстрирует черты интровертного типа. Второй этап исследования предполагал анализ неподготовленных диалогических высказываний коммуникантов в условиях спонтанного речевого общения в ходе парламентской сессии вопросов к премьер-министру. Анализ материала убеждает в существовании определенных корреляций между типом личности и предпочитаемыми речевыми стратегиями и типом аргументации.

Ключевые слова: парламентский дискурс, аргументация, экстраверсия, интроверсия, темперамент, речевая деятельность, речевое поведение, речевая стратегия.

Цитирование. Попова О. В. Особенности речевого поведения личности интровертного и экстравертного типов в парламентском дискурсе // Вестник Волгоградского государственного университета. Серия 2, Языкознание. -2018. - Т. 17, № 2. - C. 134-142. - DOI: https://doi.org/10.15688/jvolsu2.2018.2.15

\section{Введение}

Профессиональная политическая речевая деятельность социально и коммуникативно ориентирована: прямая и опосредованная, монологическая и диалогическая, подготовленная и спонтанная, она осуществляется в публичном пространстве и становится объектом разных гуманитарных наук. Возможность наблюдения за речевым поведением политиков в различных ситуациях позволяет исследователю не только эмпирически диагностировать такие личностные черты, как интроверсия / экстраверсия и эмоциональная устойчивость / нейротизм, но и установить зависимость речевых стратегий от личностных свойств и, возможно, представить закономерные связи между доминантными речевыми стратегиями и типом личности.

Цель нашего исследования - определить влияние интроверсии / экстраверсии и эмоциональной устойчивости на вербальное поведение англоязычных политиков в ситуациях прямого и опосредованного социально ориентированного общения. Гипотеза заключается в том, что в зависимости от типа личности - интровертного или экстравертного - коммуниканты используют различные виды аргументации и стратегии убеждения в ходе дискуссий и споров.

Материалом для изучения послужили подготовленные монологические и неподготовленные диалогические выступления британских политиков: премьер-министра Терезы Мэй (Theresa May): 1) первая речь по вступлении в должность; 2) презентация проекта образовательной реформы и ответы на последующие вопросы аудитории; 3) дебаты по поводу образовательной реформы в ходе традиционной сессии вопросов к премьер-министру в британском парламенте; а также выступление лидера оппозиции Джереми Корбина (Jeremy Corbyn) по окончании избирательной кампании на должность лидера лейбористской партии.

Выдвигая гипотезу, мы учитываем, что подготовленные выступления политиков (программные речи, обсуждения на митингах, заявления министров) не могут служить надежным источником информации о личности коммуниканта, поскольку политические деятели высшего ранга нередко прибегают к услугам личных помощников, спичрайтеров, специалистов по общественным связям и пр. Специфика личности наиболее ярко проявляется в спонтанных речевых актах, например в Question time- специфической сессии британского парламента, в ходе которой депутаты в устной форме задают вопросы премьер-министру или другим представителям правительства [Матвеева, Зюбина, Лесняк, 2016 ].

Формат таких встреч строго регламентирован: сессии вопросов к премьер-министру (Prime Minister's Question Time, или PMQs) проходят еженедельно по средам с 12.00 до 12.30. Список вопросов членов парламента подается заранее и публикуется в день заседания, вопросы задаются в случайном порядке, определенном компьютером. Этот порядок предполагает, что премьер-министр не знает заранее, на какой вопрос ему придется отвечать. Депутат, который первым задает вопрос по указанию спикера, начинает с формального вопроса о текущей деятельности премьера (engagements question), после чего может задать «дополнительный» (supplementary) вопрос на любую тему. Затем право задавать 


\section{МАТЕРИАЛЫ И СООБЩЕНИЯ}

вопросы переходит к лидеру оппозиции - это единственный член парламента, которому позволено задать более одного вопроса (но не больше шести) [UK Parliament Home Page]. Особенность британского парламентского дискурса - неукоснительное следование этикету, сложившемуся около двухсот лет назад, контроль за соблюдением которого осуществляется спикером. В частности, помимо запрета на использование оскорбительной лексики, действует правило обращения депутатов друг к другу исключительно в третьем лице с использованием таких формул вежливости, как the Honourable gentleman, the Honourable lady или the Honourable Member for..., с указанием избирательного округа парламентария; в отношении представителей собственной партии депутаты используют формулу my Honourable friend; министры именуются the Right Honourable gentleman. Обращение по имени и использование личного местоимения второго лица не допускается [Минаева, 2015].

\section{Методика исследования}

Согласно теории речевой деятельности, которая является методологической базой нашего исследования, всякое высказывание содержит в себе определенные отображенные элементы личности [Ермолаев, 1999; Леонтьев, 1997]. Одним из таких элементов, по мнению психологов, выступает параметр интроверсия / экстраверсия - «характеристика типических различий между людьми, крайние полюсы которой соответствуют преимущественной направленности человека либо на мир внешних объектов, либо на собственный субъективный мир» [Ильин, 2004, с. 134]. Понятия интроверсия / экстраверсия и нейротизм (эмоциональная неустойчивость) / стабильность (эмоциональная устойчивость) лежат в основе теории личности Г. Айзенка [Eysenck, 1970]. В соответствии с этой теорией людей можно разделить на четыре группы:

- стабильный интроверт (спокойный, уравновешенный, надежный, контролируемый, миролюбивый, внимательный, заботливый, пассивный);

- стабильный экстраверт (лидер, беззаботный, веселый, покладистый, отзывчивый, разговорчивый, дружелюбный, общительный);
- невротичный интроверт (легко поддающийся переменам настроения, тревожный, ригидный, рассудительный, пессимистичный, замкнутый, необщительный, тихий);

- невротичный экстраверт (ранимый, беспокойный, агрессивный, возбудимый, непостоянный, импульсивный, оптимистичный, активный).

Двухфакторная модель Г. Айзенка, используемая для определения типа личности, представляет собой пересечение двух ортогональных факторов - экстраверсии / интроверсии и эмоциональности / стабильности: «two orthogonal personality factors, extraversion / introversion and emotionality / stability» [Eysenck, 1970, с. 425]. Типы личности, выявляемые при помощи модели Айзенка, коррелируют с типами темперамента: эмоционально устойчивые типы соответствуют темпераментам сангвиника (экстраверт) и флегматика (интроверт); невротичные типы - темпераментам холерика (экстраверт) и меланхолика (интроверт). В тех случаях, когда показатели экстравертированности и нейротизма находятся на условном нуле, можно говорить о равновесном типе личности: у нее средние уровни возбуждения и торможения [Батаршев, 2001, c. 54]. Важно отметить, что экстраверсия и интроверсия, как и другие черты в понимании Г. Айзенка, представляют собой континуум, диапазон с верхним и нижним пределами, внутри которого можно расположить всех людей в зависимости от выраженности данного качества [Хьелл, Зиглер, 2003, с. 314-320].

Для определения основных черт личности Г. Айзенк разработал ряд опросников и психологических тестов, а также использовал такие методы, как самонаблюдение, исследование физических и физиологических параметров, анализ биографических сведений и экспертные оценки.

Существуют и другие эффективные способы диагностики темперамента. Такой способ, не требующий специального оборудования, был предложен Н.Н. Обозовым [Обозов, 1997]. Он предполагает изучение пятнадцати эмпирических признаков, таких как: 1) уравновешенность поведения; 2) уровень эмоционального переживания; 3) настроение; 4) речь; 5) терпение; 6) адаптация; 7) общительность; 8) агрессивность в поведении; 9) отношение к критике; 10) активность; 11) отношение к новому; 12) от- 
ношение к опасности; 13) стремление к цели; 14) самооценка; 15) внушаемость. Каждому типу темперамента свойственна определенная степень выраженности каждого из этих признаков. Н.Н. Обозов выделил 15 эмпирических признаков, характеризующих тип темперамента, А.В. Батаршев предложил использовать ту же методику для дистантной диагностики [Батаршев, 2001, с. 22].

Координация ряда лингвистических исследований с психологическими методиками диагностирования темперамента и характера позволила выявить определенные корреляции экстраверсии / интроверсии с некоторыми особенностями коммуникативно-речевого поведения. По сравнению с экстравертами у интровертов замедленная, с длительными паузами речь [Ильин, 2004, с. 137]. Экстраверты чаще и с большей легкостью совершают фатические операции, в том числе с малознакомыми людьми. В рабочей обстановке интроверты обычно поддерживают чисто деловые связи, в то время как экстраверты стремятся к эмоционально-личностным отношениям. Экспериментально было установлено, что при повышенном эмоциональном напряжении у стабильных экстравертов увеличивается словарное разнообразие и длина устного высказывания, а у невротичных интровертов эта же ситуация приводит к стереотипности словаря и уменьшению длины высказываний [Гиль, 2000, с. 51-54].

Анализ речи британских политиков и психологическая диагностика методом опроса или объективного психологического теста далеко не всегда представляются возможными, поэтому мы определяем в качестве своей задачи установление корреляции между типом темперамента и характером речевой деятельности политиков, опираясь на модель Г. Айзенка и иные сведения, подтверждающие возможность такой корреляции.

\section{Результаты и обсуждение}

Охарактеризуем особенности речевого поведения коммуникантов в ситуации, когда они выступают с подготовленной монологической речью в схожих условиях, то есть в присутствии журналистов и телекамер.

Первая речь Терезы Мэй по вступлении в должность премьер-министра была произ- несена 13 июля 2016 г. перед официальной резиденцией на Даунинг-стрит (II). Очевидно, что для политика, только что победившего на выборах, выступать впервые в таком знаковом месте - это новый опыт, сопряженный с высоким уровнем волнения. Первая речь Мэй производит впечатление тщательно отрепетированной: темп очень медленный, с акцентированными паузами. Взгляд направлен вверх и обращен в пространство, а не на присутствующих зрителей, оратор часто смотрит в текст речи. В моменты прямого обращения к зрителю взгляд оратора направлен в камеру, что также создает впечатление отрепетированного речевого поведения. Отсутствие жестикуляции свидетельствует о некоторой скованности говорящего. Из этих внешних наблюдений можно заключить: ситуация прямого спонтанного социально ориентированного общения воспринимается коммуникантом как стрессовая, что свидетельствует о его интроверсии. Свойственная интровертам направленность на внутренний субъективный мир, преувеличенное ощущение собственной значимости отражается также в выборе языковых единиц. Выступление Т. Мэй характеризуется акцентированным использованием личного местоимения первого лица:

I have just been to Buckingham Palace, where Her Majesty The Queen has asked me to form a new government, and I accepted. - Я только что была в Букингемском дворце, где Ее Величество попросила меня сформировать новое правительство, и я согласилась (здесь и далее перевод наш. - О. П.).

В отличие от Т. Мэй, Дж. Корбин в своей победной речи по окончании кампании 2015 г., приведшей к избранию его лидером лейбористской партии (I), практически не обращается к своим записям, поддерживает зрительный контакт с аудиторией, темп его речи быстрый, манера уверенная. Благодаря своих сторонников и коллег по партии, участников избирательной кампании, Корбин называет их по именам и в некоторых случаях обращается к ним напрямую:

Tom, your man to do that. - Том тот человек, кто может это сделать;

$E d$, thank you for all of that. - Эд, спасибо за все это. 


\section{МАТЕРИАЛЫ И СООБЩЕНИЯ}

Речь политика сопровождается активной жестикуляцией, подчеркивающей заинтересованность оратора в выступлении и реакции на него; вместе с тем коммуникант чутко отслеживает реакцию аудитории и точно на нее реагирует. Примечательна реакция оратора на помехи в виде аплодисментов: он ждет их окончания, не сбиваясь с мысли, и в некоторых случаях аплодирует вместе с аудиторией. Такие паралингвистические характеристики указывают на экстравертированность личности коммуниканта.

Пользуясь методом наблюдения и сопоставления по совокупности выявленных характеристик невербального поведения в различных ситуациях подготовленного и спонтанного общения, можно сделать вывод о том, что Тереза Мэй обладает меланхолическим темпераментом, который в классификации Г. Айзенка соответствует типу невротичного интроверта, а Джереми Корбин демонстрирует свойства эмоционально стабильного экстраверта, что позволяет охарактеризовать его как сангвиника.

Так как речевая деятельность социально обусловлена и по природе своей диалогична, продуцент, создавая целенаправленный текст, всегда думает о том, как он будет воспринят и какое воздействие окажет на реципиента. В процессе диалога, при непосредственном общении, у продуцента есть возможность следить за реакцией реципиента и при необходимости варьировать стратегии. Можно предположить, что у экстраверта для этого больше возможностей, поскольку постоянная направленность на мир внешних, зачастую изменчивых обстоятельств способствует большей гибкости и пластичности по сравнению с ригидными реакциями интроверта. Предпочтительный тип аргументации и выбор продуцентом наиболее эффективных средств воздействия на реципиента также может быть обусловлен типом личности. Интроверт, привыкший во всем полагаться на собственный опыт, будет приписывать свои стратегии восприятия и реципиенту, полагая, что то, что кажется убедительным ему, должно быть убедительно для всех. Экстраверт, вероятнее всего, будет полагаться на внешние источники информации: ссылаться на авторитетные мнения экспертов, приводить статистику, исторические примеры и пр.
Рассмотрим взаимодействие невротичного интроверта, которым, по-видимому, является Т. Мэй, с ее политическим оппонентом Дж. Корбином, по внешним признакам явным экстравертом, в ситуации спонтанного речевого общения во время сессии вопросов к премьер-министру, в ходе которой обсуждался представленный премьером проект образовательной реформы (IV). Суть предлагаемых изменений, направленных на повышение качества государственного среднего образования, заключается в следующем: 1) привлечение университетов к участию в школьном образовании путем спонсирования существующих или открытия собственных средних школ; 2) увеличение количества учащихся в религиозных школах (faith schools), в частности католических, за счет снятия ограничений на прием учащихся других конфессий; 3) стимулирование сотрудничества государственных школ с частными, в том числе в форме помощи в организации учебного процесса со стороны последних; 4) расширение деятельности так называемых грамматических школ (grammar schools), то есть финансируемых государством учебных заведений, практикующих отбор учащихся с одиннадцатилетнего возраста по критерию академической успеваемости (III).

Последний пункт вызвал наибольшее количество нареканий, поскольку такие школы в британском обществе зачастую рассматриваются как пережиток сегрегационной классовой системы школьного образования, существовавшей в Великобритании до конца 1960-х годов. В частности, лейбористская партия выразила резкий протест против предполагаемой реформы, о чем свидетельствует выступление ее лидера в ходе сессии вопросов к премьерминистру, посвященной этой проблеме.

Получив слово, Дж. Корбин выражает формальную благодарность спикеру, затем призывает коллег отдать дань уважения раненному накануне полицейскому и только потом переходит к обсуждению интересующей его темы образовательной реформы. Он вспоминает инаугурационную речь Т. Мэй о единстве, иронично замечая, что она достигла небывалого единства в рядах учителей, чиновников и бывших министров образования из всех фракций, выступивших против ее проек- 
та. Затем он просит назвать экспертов, одобряющих ее проект.

Т. Мэй присоединяется к соболезнованиям полицейскому и вспоминает собственный onыт работы министром внутренних дел. Перейдя к вопросу о реформе системы образования, она почти дословно повторяет слова своей программной речи (III), вопрос об эксперте игнорируется (что ее оппонент не преминул заметить).

Далее Дж. Корбин цитирует слова учителя, недовольного проектом реформы, и приводит статистику, подтверждающую неэффективность элитных школ Кента по сравнению с общеобразовательными школами Лондона в отношении успеваемости детей из бедных семей, и спрашивает, зачем поддерживать такую систему. Ответ Т. Мэй не связан с вопросом Корбина: она советует перестать смотреть в прошлое, вновь цитирует свою же программную речь и наконец заявляет:

The Right hon. Gentleman believes in equality of outcome, I believe in equality of opportunity. Уважаемый оппонент верит в равенство результатов, а мы верим в равенство возможностей;

You believe in leveling down, we believe in leveling up. - Вы верите в выравнивание по нижней границе, а мы - в выравнивание по верхней.

В своем ответе на вопрос о том, смогут ли ученики начальных школ, на месте которых планируется открыть элитные, продолжить учебу или их тоже подвергнут селекции, Мэй настаивает, что ее программа не влияет на селекцию по месту жительства, которая и так существует. Затем Мэй переходит на личности, напоминая Корбину, что сам он учился в элитной школе, так же как и она (обращзение к личному onblmy), благодаря чему они оба оказались на своем месте, и этому ее сторонники рады больше, чем его (снова переход на личности). Прямого ответа на вопрос о будущем учеников начальной школы не последовало (уход от ответа).

На вопрос Дж. Корбина, окажет ли правительство давление на действующие элитные школы, чтобы они принимали больше детей, Т. Мэй отвечает: The Right hon. Gentleman is right that what we are looking at and consulting on is a diversity in provision in education. - Уважаемый оппонент прав в том, что мы ищем разнообразия (diversity) в подходах к образованию (реплика не связана с вопросом), - затем обвиняет лейбористов в эгоизме и, наконец, переводит разговор на совершенно другую тему: улучшение показателей занятости.

Анализируя виды аргументации, применяемые коммуникантами, можно заметить существенные различия в выборе стратегий убеждения. Экстраверт Корбин опирается на внешние источники информации, его речь изобилует цитатами:

May I quote one expert at her? His name is John and he is a teacher. - Позвольте мне процитировать одного эксперта. Его зовут Джон, и он учитель;

Let me quote the Institute for Fiscal Studies. Позвольте мне процитировать Институт исследований в сфере налогообложения;

The Secretary of State for Education suggested on Monday that grammar schools may be required to set up feeder schools in poorer areas. - Глава министерства образования предположила в понедельник, что на грамматические школы будет возложена обязанность открыть собственные начальные школы в бедных районах;

Let me quote to her a critic of grammar schools. - Позвольте процитировать противника грамматических школ;

Not my words, but those of former Right hon. Member for Witney. - Это не мои слова, а слова бывшего члена парламента от Уитни;

Could I quote to her what Michael Wilshaw, the chief inspector of schools, has said? - Могу я процитировать ей, что сказал Майкл Уилшо, главный школьный инспектор?

От оппонента Дж. Корбин также требует предоставить ссылку на авторитетное мнение эксперта:

I wonder if it is possible for her.. to name any educational experts who back her proposals. - Я хотел бы знать, может ли она... назвать каких-либо экспертов от образования, кто поддерживает ее предложения.

Он обращает внимание присутствующих на то, что премьер такой информации не предоставляет или уходит от ответа на прямо поставленный вопрос:

Sadly, she wasn't able to [name any experts].К сожалению, она не смогла этого сделать; 


\section{МАТЕРИАЛЫ И СООБЩЕНИЯ}

I notice she didn't answer my question about feeder primary schools. - Я вижу, что она не ответила на мой вопрос о начальных школах;

I am sorry the Prime Minister was unable to help anyone in Kent or Buckinghamshire in the answer to my question. - Мне жаль, что премьерминистр не смогла помочь жителям Кента и Бакингемшира, ответив на мой вопрос.

В целом можно заключить, что экстраверт Корбин относится к репликам оппонента более внимательно, чем это делает интроверт Мэй. Так, в ответ на явно заготовленную заранее обвинительную фразу премьер-министра: The Right hon. Gentleman believes in equality of outcome, I believe in equality of opportunity. - Достопочтенный джентльмен верит в равенство результатов, а я верю в равенство возможностей, - Корбин отвечает, цитируя оппонента: Equality of opportunity is not segregating children at the age of 11. - Равенство возможностей не предполагает сегрегацию детей в одиннадцатилетнем возрасте. - Таким же образом Корбин обращает против Мэй ее же метафору.

Т. Мэй: Members of the Labour Party will take the advantages of a good education for themselves and pull up the ladder behind them for other people. Члены лейбористской партии оставляют себе преимущества хорошего образования и втягивают за собой лестницу, чтобы остальные не могли ей воспользоваться.

Дж. Корбин: It's not about pulling up ladders, it's about providing a ladder for every child. - Речь не о том, чтобы втягивать за собой лестницы, а о том, чтобы обеспечить лестницей каждого ребенка.

Статистические данные и цифры - это еще один способ аргументации, который использует Корбин:

In Kent, which has a grammar school system, $27 \%$ of pupils on free school meals get good GCSES compared with $45 \%$ in London. - В Кенте, где действует система элитных школ, 27 \% детей, имеющих право на бесплатное школьное питание, хорошо сдают экзамены на аттестат о среднем образовании, в то время как в Лондоне таких $45 \%$;

The problem is there are now almost a million of them on zero-hours contracts who do not know what they are going to be paid from one week to another. - Проблема в том, что почти миллион из них не имеют постоянного контракта и не знают, сколько им заплатят на каждой неделе.

Ответы Т. Мэй также содержат некоторые цифры, но, если Дж. Корбин приводит статистические данные, связанные с фактической информацией о проценте учащихся, успешно сдающих экзамены в регионах с преобладанием того или иного типа образовательной системы, премьер-министр дает оценку посещению учениками «хороших и отличных школ» и числу школьников, обучающихся в школах «плохих, не соответствующих стандарту или нуждающихся в улучшении»:

We have seen 1.4 million more children in good or outstanding schools. - Мы видим на 1,4 миллиона больше детей в хороших и отличных школах;

We will ensure that we are able to provide good school places for the 1.25 million children in schools that are failing, inadequate or that need improvement. - Мы добьемся того, чтобы обеспечить местами в хороших школах 1,25 миллиона детей, обучающихся в школах плохих, не соответствующих стандарту или нуждающихся в улучшении.

В отличие от экстраверта, ищущего подтверждение своей правоты вовне, личности интровертированного типа свойственно, как мы уже отмечали, ссылаться в качестве аргументации на собственный опыт:

One of the events that I used to look forward to going to every year as Home Secretary was the Police Bravery Awards. - Одним из тех событий, в которых я с радостью участвовала каждый год, будучи министром внутренних дел, была церемония вручения полицейским наград за отвагу;

I gently remind the Right hon. Gentleman that he went to a grammar school. - Позвольте напомнить достопочтенному джентльмену, что он учился в грамматической школе;

I went to a grammar school... - Я училась в грамматической школе...

.... and it is what got us to where we are todayи благодаря этому мы достигли того, что имеем сегодня.

Речь Т. Мэй содержит множество повторов: формулировка фразы, которая кажется ей удачной, повторяется дословно:

What I want to see is more good school places and a diversity of provision of education in this 
country... and young people going as far as their talents will take them. - Я хочу видеть больше мест в хороших школах и разнообразие в подходах к образованию... чтобы молодые люди могли пойти так далеко, как им позволит талант;

We will ensure that we are able to provide good school places for the 1.25 million children that are in schools that are failing or inadequate... It is an opportunity for young people to go where their talents will take them. - Мы сделаем все, чтобы обеспечить местами в хороших школах 1,25 миллиона детей... это возможность для молодых людей пойти, куда им позволит талант;

We are setting up a more diverse education system that provides more opportunities... I want to ensure that children have the ability to go where their talents take them. - Мы создаем более разнообразную систему образования, предоставляющую больше возможностей... Я хочу сделать все, чтобы дети могли пойти, куда им позволяет талант;

The Right hon. Gentleman is right that what we are looking at and consulting on is a diversity in provision in education. - Уважаемый оппонент прав в том, что мы ищем и рассматриваем пути к большему разнообразию в подходах к образованию.

Таким образом, можно заключить, что особенностью речевого поведения политика экстравертного типа является аргументация с опорой на факты из внешних источников (мнения экспертов и статистические данные), в то время как в речевом поведении политика интровертного типа преобладает аргументация, основанная на личном субъективном опыте, в его речи изобилуют повторы, стратегии убеждения отличаются ригидностью.

\section{Выводы}

Наблюдение за вербальным и невербальным поведением политиков в различных ситуациях социально ориентированного общения дает возможность, во-первых, охарактеризовать темперамент политика, уровень его экстравертированности или интровертированности, а также эмоциональной стабильности; во-вторых, выявить определенную корреляцию между типом личности и предпочитаемыми вербальными стратегиями в подготовленной монологической и неподготовленной диалогической речи. При обдумывании и подготовке аргументации интроверт склонен выбирать такие стратегии, которые оказали бы наибольшее воздействие на него самого, прежде всего обращение к собственному опыту. Общение с малознакомыми людьми для невротичного интроверта сопряжено с высоким уровнем стресса. Вербальные стратегии отличаются ригидностью: интроверту трудно переформулировать высказывание, он часто прибегает к повторам, иногда дает ответ, не соответствующий вопросу. Интроверт невнимателен к реакциям партнера, уходит от ответа на прямой вопрос, в ответ на критику переходит на личности. Экстраверт, напротив, чутко реагирует на реплики оппонента, способен удачно обратить их в свою пользу. При подготовке аргументации экстраверт не полагается на свой опыт, но прибегает к внешним источникам информации.

\section{СПИСОК ЛИТЕРАТУРЫ}

Батаршев А. В., 2001. Темперамент и характер: Психологическая диагностика. М. : ВЛАДОС-ПРЕСС. $336 \mathrm{c}$.

Гиль О. Г., 2000. Речевые проявления личности в устном рассказе нарративного типа : дис. ... канд. филол. наук. М. $271 \mathrm{c.}$

Ермолаев А. К., 1999. Моделирование личности по тексту: обобщение опыта оперативно-розыскной работы : дис. ... канд. филол. наук. Барнаул. $173 \mathrm{c}$.

Ильин Е. П., 2004. Психология индивидуальных различий. СПб. : Питер. 701 c.

Леонтьев А. А., 1997. Основы психолингвистики. М. : Смысл. $287 \mathrm{c}$.

Матвеева Г. Г., Зюбина И. А., Лесняк М. В., 2016. Особенности жанровой системы парламентского дискурса // Политическая лингвистика. №4 (58). C. 133-138.

Минаева Л. В., 2015. Британский парламентский дискурс как культурный феномен // Преподаватель XXI век. № 3, ч. 2. С. 396-404. URL: https://cyberleninka.ru/article/n/britanskiyparlamentskiy-diskurs-kak-kulturnyy-fenomen (дата обращения: 10.09.2017).

Обозов Н. Н., 1997. Типы личности, темперамент и характер. СПб. : Акад. психологии, предпринимательства и менеджмента. $36 \mathrm{c.}$

Хьелл Л., Зиглер Д., 2003. Теории личности (Основные положения, исследования, применение). 3-е изд. СПб. : Питер. 608 с.

Eysenck H. J., 1970. The Structure of Human Personality. London : Methuen. $476 \mathrm{c}$.

UK Parliament Home Page. URL: http://www. parliament.uk/about/how/business/questions/ (date of access: 12.09.2017). 


\section{МАТЕРИАЛЫ И СООБЩЕНИЯ}

\section{ИСТОЧНИКИ}

I - Jeremy Corbyn elected Labour leader: victory speech in full. URL: https://www.youtube.com/ watch? $\mathrm{v}=\mathrm{wB} 8 \mathrm{EMRgVV} 1 \mathrm{U}$ (date of access: 03.09.2017).

II - Theresa May: First speech as Prime Minister (BBC News). URL: https://www.youtube.com/ watch? $\mathrm{v}=$ FDyZ8trge2E (date of access: 09.07.2017).

III - Theresa May's full 'great meritocracy' speech (September $9^{\text {th }}$ 2016). URL: https://www. youtube.com/watch? $\mathrm{v}=2 \mathrm{MudOTi5z3I}$ (date of access: 10.07.2017).

$I V$ - Prime Minister's Questions (14 September 2016). URL: https://www.youtube.com/watch?v=jSox Dk879n8\&index $=25 \&$ list $=$ PL40441042C458B62B (date of access: 12.07.2017).

\section{REFERENCES}

Batarshev A.V., 2001. Temperament and character: Psychological diagnostics. Moscow, VLADOSPRESS Publ. 336 p.

Gil O.G., 2000. Speech manifestations of personality in oral narrative. Cand. philol. sci. diss. Moscow. 271 p.

Ermolaev A.K., 1999. Modelling personality by text: Summary of investigative work. Cand. philol. sci. diss. Barnaul. 173 p.

Ilyin E.P., 2004. The psychology of individual differences. Saint Petersburg, Piter Publ. 701 p.

Leontyev A.A., 1997. The basics of psycholinguistics. Moscow, Smysl Publ. 287 p.

Matveeva G.G., Zyubina I.A., Lesnyak M.V., 2016. The peculiarities of the parliamentary discourse's genre system. Politicheskaya lingvistika [Political Linguistics Journal], no. 4 (58), pp. 133-138.

Minaeva L.V., 2015. The British parliamentary discourse as a phenomenon of culture. Prepodavatel XXI vek, no. 3, part 2, pp. 396-404. URL: https:// cyberleninka.ru/article/n/britanskiyparlamentskiy-diskurs-kak-kulturnyy-fenomen. (accessed 10 September 2017).

Obozov N.N., 1997. Personality types, temperament and character. Saint Petersburg, Akad. psikhologii, predprinimatelstva i menedzhmenta Publ. $36 \mathrm{p}$.

Hjelle L., Zigler D., 2003. Personality theories. Saint Petersburg, Piter Publ. 608 p.

Eysenck H.J., 1970. The Structure of Human Personality. London, Methuen. 476 p.

UK Parliament Home Page. URL: http://www. parliament.uk/about/how/business/questions/. (accessed 12 September 2017).

\section{SOURCES}

Jeremy Corbyn elected Labour leader: victory speech in full. URL: https://www.youtube.com/watch?v= wB8EMRgVV1U. (accessed 3 September 2017).

Theresa May: First speech as Prime Minister (BBC News). URL: https://www.youtube.com/ watch? $\mathrm{v}=$ FDyZ8trge2E. (accessed 9 July 2017).

Theresa May's full 'great meritocracy' speech (September $9^{\text {th }}$ 2016). URL: https://www.youtube. $\mathrm{com} /$ watch? $\mathrm{v}=2$ MudOTi5z3I. (accessed 10 July 2017).

Prime Minister's Questions (14 September 2016). URL: https://www.youtube.com/watch? $\mathrm{v}=\mathrm{j}$ SoxDk 879n8\&index $=25 \&$ list $=$ PL40441042C458B62B. (accessed 12 July 2017).

\section{Information about the Author}

Olga V. Popova, Postgraduate Student, Department of General and Comparative Linguistics, Moscow State Linguistic University, Ostozhenka St., 38/1, 119034 Moscow, Russia, domolgi@rambler.ru, https://orcid.org/0000-0002-1418-3704

\section{Информация об авторе}

Ольга Валентиновна Попова, аспирант кафедры общего и сравнительного языкознания, Московский государственный лингвистический университет, ул. Остоженка, 38, стр. 1, 119034 г. Москва, Россия, domolgi@rambler.ru, https://orcid.org/0000-0002-1418-3704 